Pesq. Vet. Bras. 37(9):995-1001, setembro 2017 DOI: $10.1590 / \mathrm{S} 0100-736 \mathrm{X} 2017000900016$

\title{
Anatomia microscópica e ultraestrutura do joelho da paca (Cuniculus paca Linnaeus, 1766) ${ }^{1}$
}

\begin{abstract}
Alessandra Silva² ${ }^{2}$ Leandro L. Martins ${ }^{3}$, Sergio P. Garcia-Filho ${ }^{4}$, Fabricio S. de Oliveira ${ }^{2}$, Tais H.C. Sasahara ${ }^{2 *}$, Cintia R.N. Tosta ${ }^{5}$, Paola C. Moraes ${ }^{2}$ e Márcia R.F. Machado ${ }^{2}$

ABSTRACT.- Silva A., Martins L.L., Garcia-Filho S.P., Oliveira F.S., Sasahara T.H.C., Tosta C.R.N., Moraes P.C. \& Machado M.R.F. 2017. [Microscopic anatomy and ultrastructure of paca stifle (Cuniculus paca Linnaeus, 1766).] Anatomia microscópica e ultraestrutura do joelho da paca (Cuniculus paca Linnaeus, 17'66). Pesquisa Veterinária Brasileira 37(9):995-1001. Faculdade de Ciências Agrárias e Veterinárias, Universidade Estadual Paulista, Universidade Estadual Paulista, Via de Acesso Prof. Paulo Donato Castellane s/n, Jaboticabal, SP 14884-900, Brazil. E-mail: tsasahara@gmail.com

Paca (Cuniculus paca), one of the largest rodent of the Brazilian fauna, has characteristics inherent to the species that can contribute as a new experimental animal; so, considering that there is a growing search for experimental models suitable for orthopedic and surgical research, it was analyzed and described in detail the microscopic and ultrastructural anatomy of the stifle in this rodent. The collateral ligaments are composed of bundles of collagen fibers arranged in parallel and in wavy path. Fibroblasts formed parallel rows to the collagen fibers; concerning the collateral ligaments, they presented imperceptible cytoplasm at light microscopy, but at ultrastructure analysis they presented several cytoplasmic processes. At the microscopic level, the stifle of paca resembles the domestic animals, rodents and lagomorphs.
\end{abstract}

INDEX TERMS: Ligaments, menisci, light microscopy, electron microscopy, rodent.

RESUMO.- A paca (Cuniculus paca), um dos maiores roedores da fauna brasileira, possui características inerentes à sua espécie que podem contribuir como uma nova opção de animal experimental; assim, considerando-se que há crescente busca por modelos experimentais apropriados para ortopedia e pesquisas cirúrgicas, foram analisados e descritos em detalhes a anatomia microscópica e ultraestrutural do joelho desse roedor. Os ligamentos colaterais são constituídos por feixes de fibras colágenas arranjadas paralelamente e com trajeto ondulado. Os fibroblastos for-

\footnotetext{
${ }^{1}$ Recebido em 23 de agosto de 2016.

Aceito para publicação em 14 de dezembro de 2016.

${ }^{2}$ Faculdade de Ciências Agrárias e Veterinárias (FCAV), Universidade Estadual Paulista (Unesp), Campus de Jaboticabal, Via de Acesso Prof. Paulo Donato Castellane s/n, Jaboticabal, SP 14884-900, Brasil. *Autor para correspondência: tsasahara@gmail.com

${ }^{3}$ Departamento de Medicina Veterinária, Universidade Estadual de Maringá, Campus Umuarama, Estrada da Paca s/n, Bairro São Cristóvão, Umuarama, PR 87507-190, Brasil.

${ }^{4}$ Departamento de Medicina Veterinária, Faculdade Ingá (Uningá), Rod. PR- 317, 6114, Maringá, PR 87035-510, Brasil.

${ }^{5}$ Laboratório de Anatomia Animal, Departamento de Morfologia, Universidade Federal de Uberlândia (UFU), Avenida Pará, Bloco 2U, Umuarama, Uberlândia, MG 38400-902, Brasil.
}

mavam fileiras paralelas às fibras colágenas; quanto aos ligamentos colaterais, estes apresentaram citoplasma imperceptível à avaliação por microscopia de luz, entretanto, em análise ultraestrutural verificou-se vários prolongamentos citoplasmáticos. Microscopicamente, as estruturas presentes no joelho da paca assemelham-se às dos animais domésticos, roedores e lagomorfos.

TERMOS DE INDEXAÇÃO: Ligamentos, meniscos, microscopia de luz, microscopia eletrônica, roedor.

\section{INTRODUÇÃO}

A paca é o segundo maior roedor da fauna brasileira, apresenta corpo robusto e vigoroso, nos machos e fêmeas adultos, o comprimento médio entre o nariz e a ponta da cauda é de $70 \mathrm{~cm}$ e $60 \mathrm{~cm}$, respectivamente e o peso corpóreo varia de cinco a $10 \mathrm{~kg}$, podendo chegar até aos $14 \mathrm{~kg}$ (Mondolfi 1972, Matamoros 1982).

Geograficamente a paca está distribuída do Sudoeste do México ao Sul do Brasil, vivendo em áreas cobertas com vegetação alta, tais como matas e capoeirões, sempre próximos aos rios ou riachos, pois estes animais têm o costume de mergulhar (Silva 1994).

Sua importância, além da comercial, atinge também o 
âmbito da ciência podendo ser uma boa alternativa para fins de pesquisa, modelo animal e conhecimento como forma de preservação da espécie (Santos 2006).

Projetos voltados ao melhor conhecimento sobre a morfologia da paca (Cuniculus paca), roedor que integra a fauna brasileira, vêm sendo desenvolvidos, já há algum tempo, no Laboratório de Anatomia em conjunto com o Setor de Animais Silvestres, ambos da Faculdade de Ciências Agrárias e Veterinárias, Campus de Jaboticabal da Universidade Estadual Paulista (FCAV- Unesp), sendo esse Setor devidamente credenciado pelo IBAMA como criatório experimental.

Considerando a procura por modelos animais para cirurgias experimentais, adequados para desenvolvimento de habilidades e técnicas cirúrgicas (Romão et al. 2011), e tendo em vista que o estudo da anatomia comparada dos animais vertebrados é uma etapa fundamental para concepção de modelo animal adequado e generalizável (Bradley 1959), objetivou-se, com o presente estudo, descrever microscopicamente e ultraestruturalmente os componentes do joelho da paca.

\section{MATERIAL E MÉTODOS}

Neste trabalho foram utilizadas pacas adultas do plantel do Setor de Animais Silvestres do Departamento de Zootecnia da Faculdade de Ciências Agrárias e Veterinárias de Jaboticabal, Unesp. Este criatório é registrado junto ao Instituto Brasileiro do Meio Ambiente e dos Recursos Naturais Renováveis (IBAMA), como criatório de espécimes da fauna brasileira para fins científicos, número do cadastro 482508. A metodologia adotada neste estudo foi aprovada pela Comissão de Ética no Uso de Animais (CEUA), da Faculdade de Ciências Agrárias e Veterinárias, Campus de Jaboticabal da Universidade Estadual Paulista "Júlio de Mesquita Filho" (FCAV - UNESP), sob o protocolo de número 20.543/10.

Para o estudo foram utilizados oito espécimes adultos (um macho e sete fêmeas), descartados para seleção e manutenção do equilíbrio entre machos e fêmeas do plantel. Destes animais, quatro foram destinados para análise à microscopia de luz e quatro destinados para análise à microscopia eletrônica.

A eutanásia foi realizada mediante sedação prévia com meperidina $(3 \mathrm{mg} / \mathrm{Kg})$ associada a midazolan $(1 \mathrm{mg} / \mathrm{Kg})$ pela via intramuscular, anestesia geral com quetamina $(25 \mathrm{mg} / \mathrm{kg})$ e xilazina $(0,5 \mathrm{mg} / \mathrm{Kg})$ também pela via intramuscular, e por fim injeção intracardíaca de cloreto de potássio 19,1\%, dose-efeito, até a parada cardiorrespiratória (Leal et al. 2014). Após a eutanásia, procedeu-se a dissecação do joelho para exposição, identificação e colheita dos ligamentos colaterais lateral e medial e meniscos lateral e medial de oito animais.

\section{Microscopia de luz}

0 material colhido das pacas (1 e 2) foi fixado em Bouin por 24 horas e mantido em álcool 70\%. Os meniscos foram, então, divididos em região cranial, região média e região caudal. As regiões craniais foram descalcificadas com solução de ácido fórmico a 30\% e citrato de sódio a 20\% (1:1) por 31 horas, e em seguida, foram lavadas em água corrente até retirar toda solução descalcificante e colocadas em álcool 70\%. Posteriormente, os ligamentos e os meniscos foram seccionados em fragmentos menores os quais foram desidratados, diafanizados e incluídos em parafina plástica (paraplast).

O material colhido das pacas (3 e 4) foi fixado em solução de McDowell (paraformaldeído a 4\% e glutaraldeído a 1\% em tampão fosfato salino 0,1M; pH 7,4) por 24 horas. Depois de fixados foram mantidos em solução de tampão fosfato salino $(0,1 \mathrm{M}$; pH $7,4)$ a $4^{\circ} \mathrm{C}$. Após a fixação, os meniscos foram divididos em região cranial, região média e região caudal. As regiões médias e caudais permaneceram em solução de tampão fosfato salino $(0,1 \mathrm{M}$; $\mathrm{pH}$ $7,4)$ a $4^{\circ} \mathrm{C}$. As regiões craniais foram descalcificadas com solução de ácido fórmico a $30 \%$ e citrato de sódio a $20 \%$ na proporção 1:1 por período de 31 horas e em seguida foram lavadas em água corrente até retirar toda solução descalcificante e colocadas em solução de tampão fosfato salino $(0,1 \mathrm{M} ; \mathrm{pH} 7,4)$.

Posteriormente, os ligamentos colaterais e os meniscos foram seccionados em fragmentos menores e desidratados em solução de álcool 80\% durante 24 horas. Foram realizadas duas lavagens, uma em álcool $90 \%$ e outra em álcool absoluto, com duração de 30 minutos cada uma. Em seguida, as amostras foram incluídas em historesina (Kit Leica Historesin).

As preparações histológicas foram obtidas mediante cortes semi-seriados, em micrótomo automático (Leica, RM-2155), com auxílio de navalhas descartáveis, obtendo-se cortes de cinco micrômetros que foram corados com Tricrômico de Masson (Vitorino 1979). Já o material incluído em historesina foi seccionado utilizando-se navalhas de vidro, obtendo-se cortes semi-seriados de um a três micrômetros, corados com HE segundo Tolosa et al. (2003). As lâminas histológicas foram analisadas em microscópio Leica DM5000B, acoplado à câmera Leica DFC300FX e as imagens capturadas para o documentação digital.

\section{Ultraestrutura}

Microscopia eletrônica de varredura. 0 material colhido das pacas (5 e 6) foi fixados em solução de glutaraldeído 2,5\% por 24 horas. Após a fixação foram lavados em tampão fosfato salino $(0,1 \mathrm{M}$; pH 7,4); pós-fixados em tetróxido de ósmio $1 \%$ por duas horas; lavados novamente em tampão fosfato salino $(0,1 \mathrm{M}$; $\mathrm{pH}$ 7,4); desidratados em série crescente de concentração de álcoois.

Em seguida, foram secos em secadora de ponto crítico com $\mathrm{CO}_{2}$ líquido em aparelho BAL-TEC, montados em suporte de cobre, metalizadas com ouro paládio em aparelho DENTON VACUM DESK II e observados em microscópio eletrônico de varredura (JEOL-JSM 5410 Tóquio, Japão) para captura da imagem. Todo procedimento foi realizado no Laboratório de Microscopia Eletrônica da FCAV-Unesp.

Microscopia eletrônica de transmissão. 0 material colhido das pacas (7 e 8) foi fixado em solução de glutaraldeído 2,5\% por 4 horas. Depois de fixados foram lavados em tampão fosfato salino $(0,1 \mathrm{M} ; \mathrm{pH} 7,4)$.

Após a fixação, os meniscos foram divididos em região cranial, região média e região caudal. As regiões médias e caudais permaneceram em solução de tampão fosfato salino $(0,1 \mathrm{M} ; \mathrm{pH} 7,4)$. As regiões craniais foram descalcificadas com solução de ácido etilenodiaminotetracético (EDTA) por dois meses com troca de solução semanalmente, e em seguida, foram lavadas em solução de tampão fosfato salino (0,1M; pH 7,4) até retirar toda solução descalcificante e colocadas em solução de tampão fosfato salino $(0,1 \mathrm{M} ; \mathrm{pH} 7,4)$.

Posteriormente, as amostras foram seccionadas em fragmentos menores e, em seguida, passaram por três lavagens em tampão fosfato de sódio $(0,1 \mathrm{M}$; pH 7,4) por 12 horas; três lavagens em frasco de vidro por cinco minutos cada; pós fixação em tetróxido de ósmio a $1 \%$ em solução de tampão fosfato de sódio $(0,1 \mathrm{M} ; \mathrm{pH}$ 7,4 ) por duas horas a $4^{\circ} \mathrm{C}$. Em continuidade, procedeu-se a desidratação em série crescente de concentração de acetona.

Em seguida, procedeu-se a infiltração da resina. As amostras foram, então, colocadas em moldes de polietileno, próprios para a inclusão e acondicionadas em estufa à $60^{\circ} \mathrm{C}$ por 72 horas. Cortes semifinos, corados em azul de toluidina e os cortes ultrafinos contrastados com acetato de uranila e citrato de chumbo foram realizados em ultramicrótomo. 
As grades foram avaliadas ao microscópio eletrônico de transmissão JEOL ${ }^{\circledR}$ JEM 1010 Tokyo, Japão), operando com feixe de elétrons de $80 \mathrm{keV}$ e as imagens capturadas com auxilio de câmera digital Kodak Megaplus (1.4i, 1.6i ou 4.2i ccd) no Laboratório de Microscopia Eletrônica da FCAV-UNESP.

\section{RESULTADOS}

\section{Ligamentos colaterais lateral e medial}

Mediante as análises à microscopia de luz observaram-se fibras de colágeno organizadas paralelamente umas às outras e com ondulações ao longo das fibras colágenas. Entre as fibras de colágeno havia fibroblastos com núcleos alongados, corados em azul, dispostos em filas paralelas as fibras de colágeno, e com citoplasma imperceptível. Encontrou-se também tecido conjuntivo frouxo com aglomerado de células com núcleos de formato irregular, e vaso sanguíneo com hemácias, entre os feixes de fibras colágenas longitudinais (Fig.1a,b).

$\mathrm{Na}$ microscopia eletrônica de varredura as fibras de
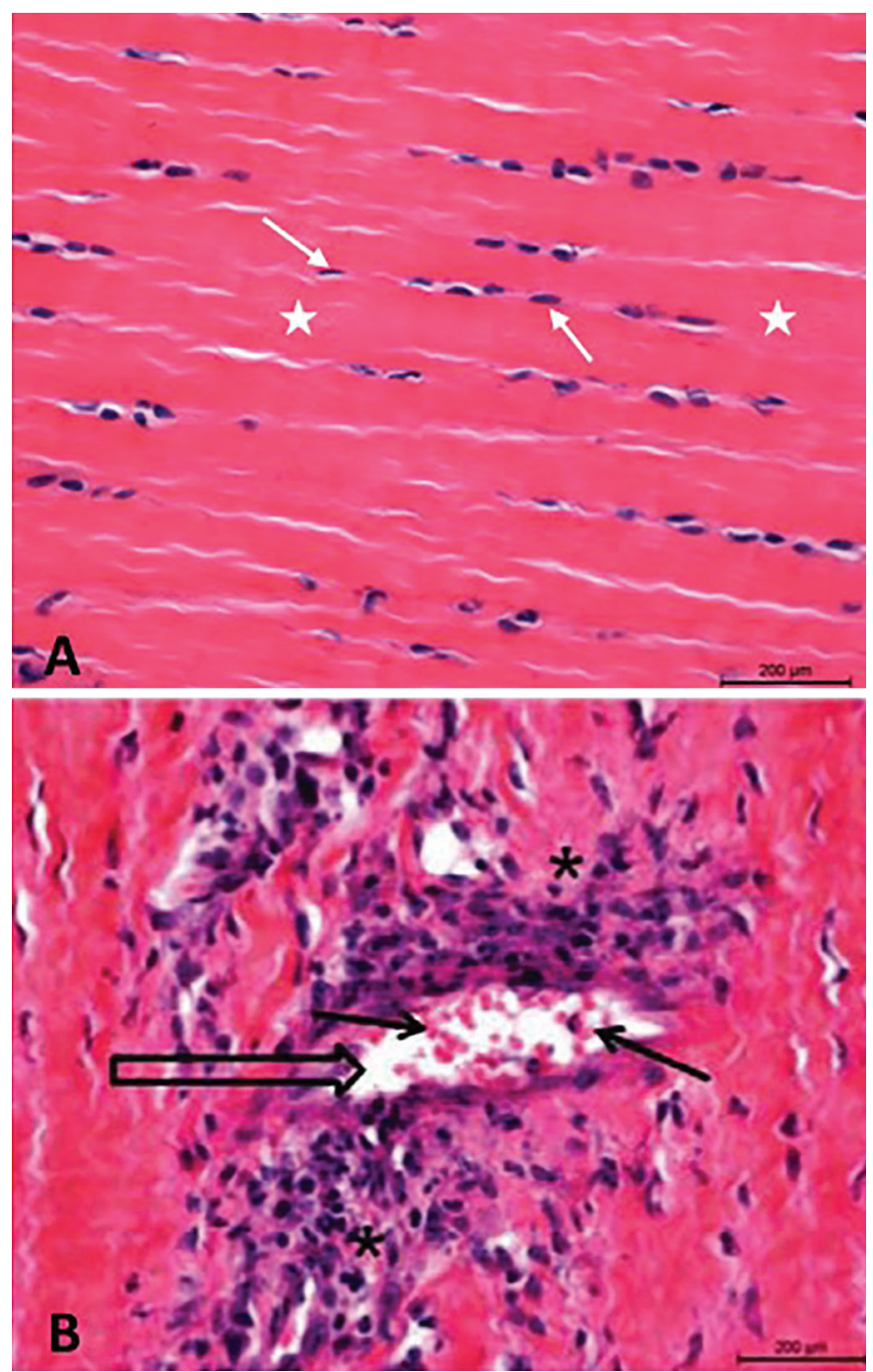

Fig.1. (A) Ligamento colateral lateral (joelho esquerdo) de paca adulta, onde se observa $\left({ }^{*}\right)$ tecido conjuntivo denso modelado e núcleos de fibroblastos (setas) dispostos em fileiras. (B) Ligamento colateral medial (joelho esquerdo) de paca adulta, onde se observa tecido conjuntivo frouxo (asteriscos), vaso sanguíneo (seta vazada) e hemácias (seta). HE.

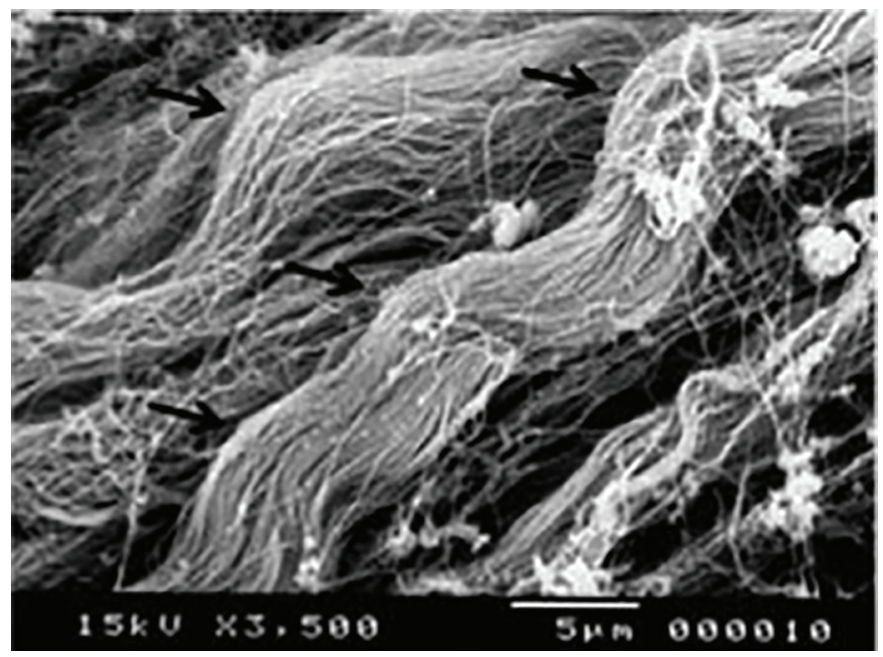

Fig.2. Fotoeletromicrografia de varredura do ligamento colateral lateral (joelho esquerdo) de paca adulta, onde se observa a organização paralela das fibras de colágeno com trajeto ondulado (setas).

colágeno apresentaram-se como estruturas cilíndricas, alongadas e com ondulações ao longo do seu comprimento. Também foi possível observar o arranjo das fibras de colágeno paralelas uma às outras, agrupadas em feixes e com orientação definida (Fig.2).

Na microscopia eletrônica de transmissão foram identificadas as fibrilas de colágeno paralelas umas às outras que se agrupavam em feixes para compor as fibras de colágeno. As fibrilas de colágeno exibiam estriações transversais pouco espaçadas que se repetiam periodicamente (Fig.3a). Foram observados fibroblastos que apresentavam núcleos achatados e alongados, citoplasma delgado com vários prolongamentos que se estendiam a partir do corpo da célula e se projetavam entre as fibrilas de colágeno (Fig.3b).

\section{Meniscos lateral e medial}

Nas análises à microscopia de luz observou-se tecido ósseo imerso em cartilagem hialina e fibrocartilagem. Verificou-se na periferia da cartilagem hialina matriz homogênea, avascular, com lacunas e dentro das lacunas havia condrócitos que variavam de formato achatado a alongado. Na região profunda desta cartilagem, os condrócitos apresentavam formato arredondado e algumas vezes apareciam em grupos isógenos (Fig.4a).

No tecido ósseo, presente na região cranial dos meniscos, havia camada de osso lamelar com trabéculas ósseas internamente. As trabéculas estavam separadas por espaços intercomunicantes contendo medula óssea. Na superfície da trabécula óssea observou-se osteoblastos dispostos lado a lado e no interior da matriz óssea estavam os osteócitos, cada um em sua lacuna (Fig.4b).

Nas amostras das regiões média e caudal dos meniscos, lateral e medial do joelho da paca foram identificados feixes de fibras colágenas com orientação irregular. Entre os feixes de fibras colágenas havia núcleos de condrócitos com formato arredondado e dispostos em fileiras (Fig 5). A organização observada neste tecido é característico de tecido fibrocartilaginoso. 

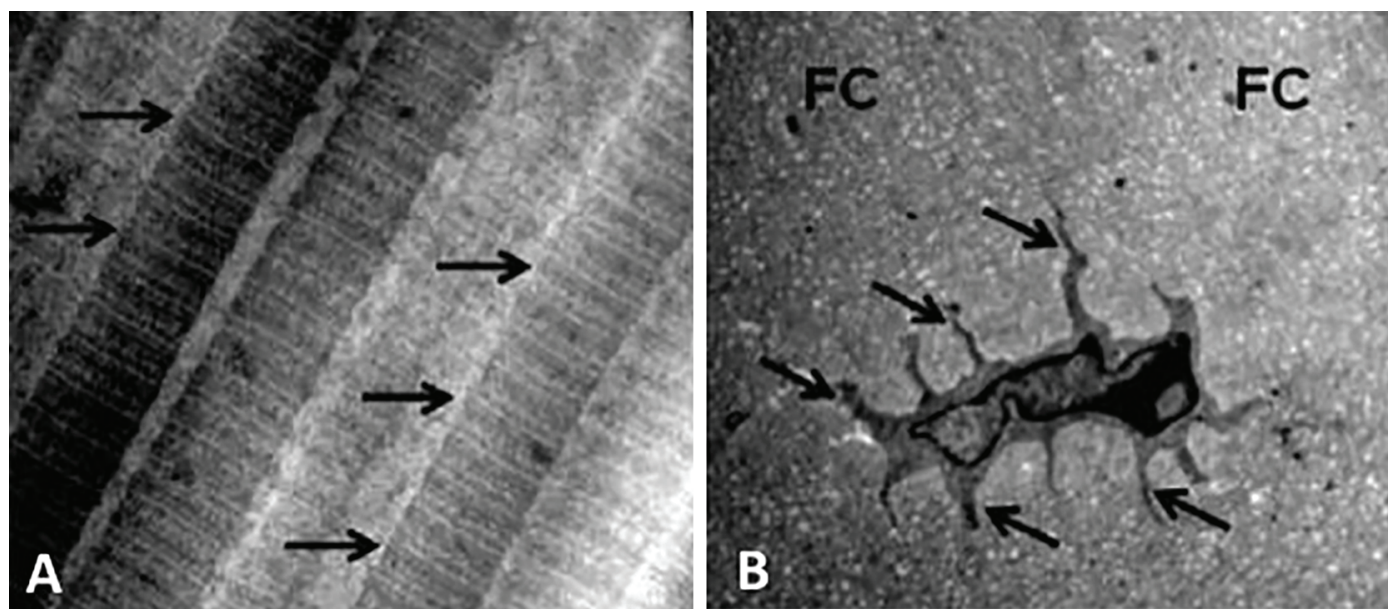

Fig.3. Fotoeletromicrografia de transmissão (A) do ligamento colateral (joelho esquerdo) de paca adulta, onde se observa no ligamento colateral lateral, as fibrilas de colágeno e sequência de estriações transversais (setas) que se repetem ao longo das fibrilas, (B) no ligamento colateral medial, o fibroblasto com vários prolongamentos citoplasmáticos (setas) projetando-se entre as (FC) fibras de colágeno.
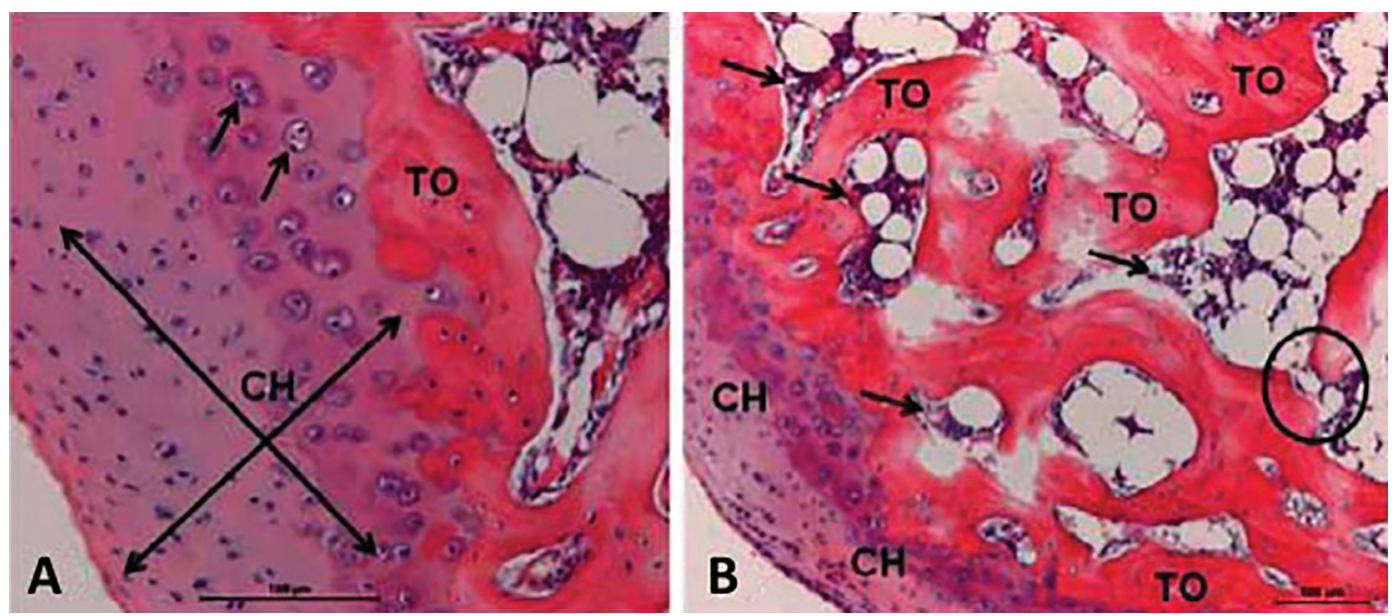

Fig.4. (A) Região cranial do menisco medial (joelho esquerdo) de paca adulta, onde se observa: grupos isógenos de condrócitos (setas) na cartilagem hialina (CH) e o tecido ósseo (TO); (B) cartilagem hialina (CH), tecido ósseo (TO), trabéculas ósseas separadas por espaços intercomunicantes (círculo) contendo a medula óssea (setas). HE.

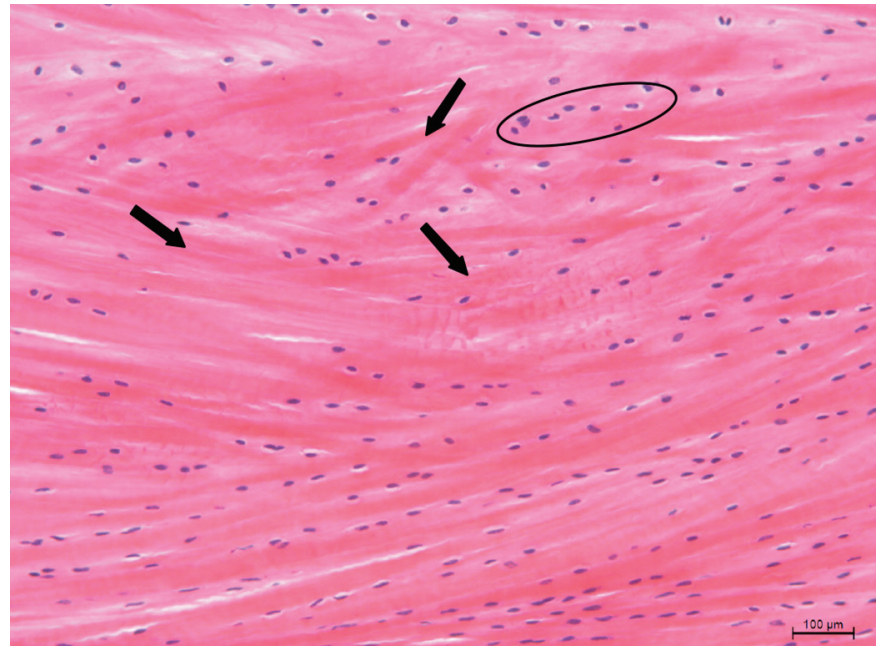

Fig.5. Região caudal do menisco medial (joelho direito) de paca adulta, onde se observa a orientação irregular das fibras de colágeno (setas) e núcleos de condrócitos dispostos em fileiras (círculo). HE.
0 arranjo irregular e entrelaçado das fibras de colágeno pôde ser observado à microscopia eletrônica de varredura e transmissão nas amostras das regiões média e caudal dos meniscos lateral e medial do joelho (Fig.6a,b). Verificou-se, à microscopia eletrônica de transmissão presença de condrócitos, fibroblastos e células consideradas transitórias, similares a fibroblasto ou condrócito. Observou-se na matriz óssea osteócitos, cada um em sua lacuna (Fig 7a). Na superfície das trabéculas havia osteoblastos posicionados lado a lado e nos espaços intercomunicantes das trabéculas pôde-se verificar a medula óssea (Fig.7b).

\section{DISCUSSÃO}

\section{Ligamentos colaterais, lateral e medial}

Os ligamentos colaterais lateral e medial do joelho das pacas são constituídos por tecido conjuntivo denso modelado em grande parte de sua extensão, assim como descrito para os ligamentos cruzados cranial e caudal para o ligamento colateral medial, para o tendão patelar e para o 

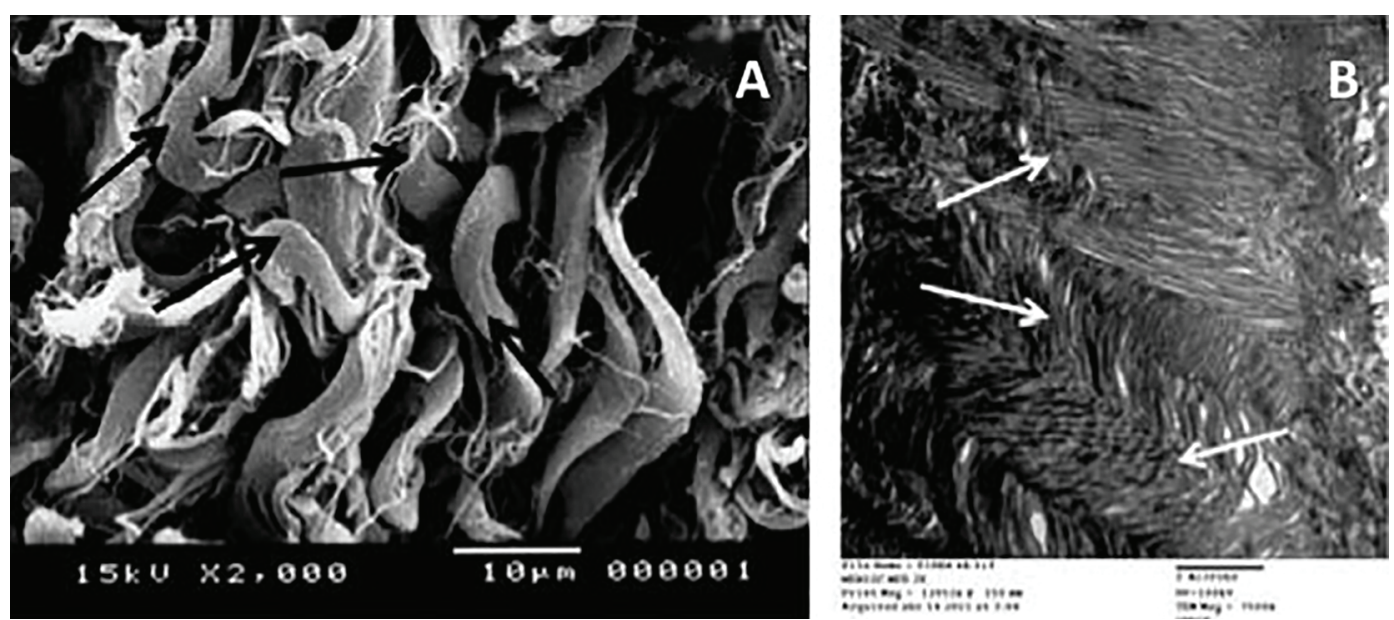

Fig.6. (A) Fotoeletromicrografia de varredura da região caudal do menisco lateral (joelho direito) de paca adulta: onde nota-se a disposição irregular das fibras de colágeno (setas). (B) Fotoeletromicrografia de transmissão, onde nota-se a disposição irregular das fibras de colágeno (setas).
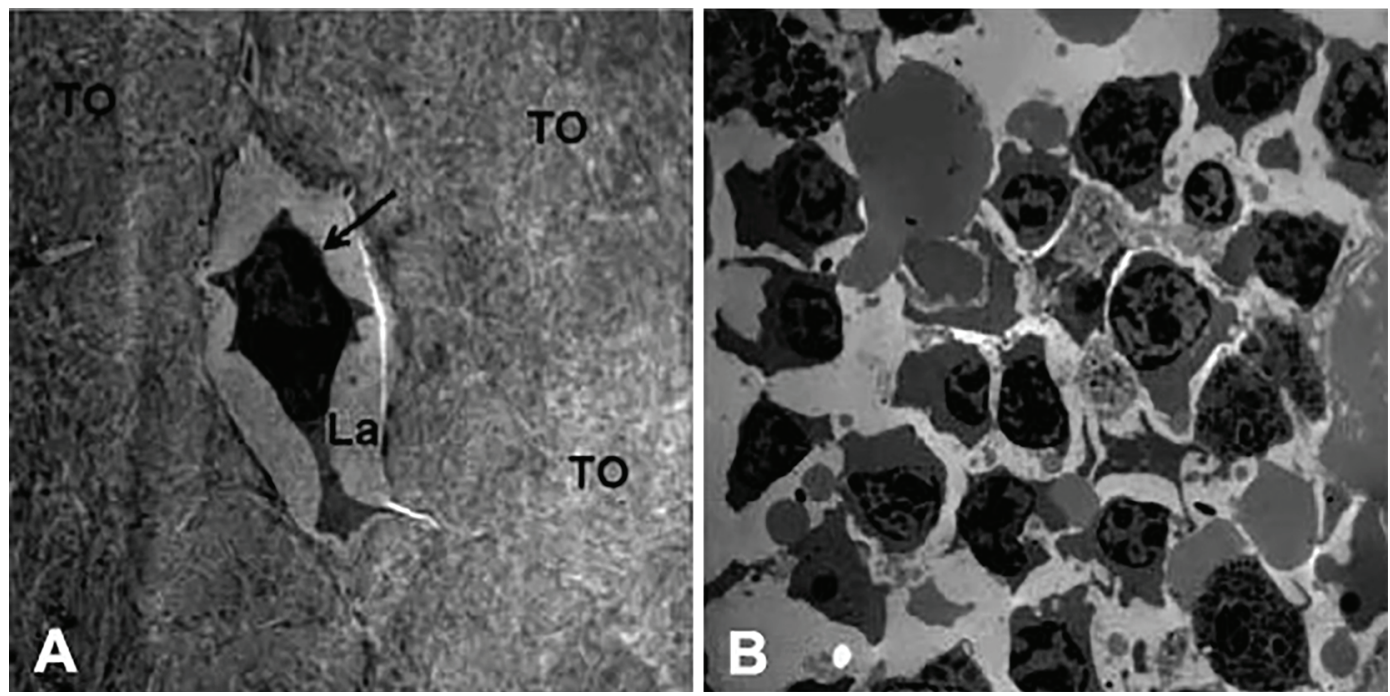

Fig.7. Fotoeletromicrografia de transmissão da (A) região cranial do menisco lateral (joelho direito) de paca adulta, onde nota-se no tecido ósseo (TO) a presença de osteócito (seta) em sua lacuna (La), (B) medula óssea.

tendão calcâneo comum de coelhos da raça Nova Zelândia (Amiel et al. 1984); para o ligamento colateral lateral de seres humanos (Mendes \& Silva 2006) e para o ligamento cruzado cranial de ovinos (Meller et al. 2009).

A predominância de fibroblastos dispostos em fileiras, paralelas aos feixes de fibras colágenas, verificada nos ligamentos cruzados cranial e caudal, no ligamento colateral medial, no tendão patelar e no tendão calcâneo comum de coelhos da raça Nova Zelândia (Amiel et al. 1984); no ligamento colateral lateral de seres humanos (Mendes \& Silva 2006) e no ligamento cruzado cranial de ovinos (Meller et al. 2009) também foi observada nos ligamentos colaterais lateral e medial do joelho da paca.

Observou-se fibroblastos alongados entre fibrilas de colágeno de formato circular em corte transversal nos ligamentos colaterais lateral e medial, assim como descrito para o ligamento cruzado cranial de seres humanos (Strocchi et al. 1992).

0 arranjo paralelo e o trajeto ondulado das fibras colágenas descrito para os ligamentos cruzados cranial e cau- dal, para o ligamento colateral medial, para o tendão patelar e para o tendão calcâneo comum de coelhos da raça Nova Zelândia (Amiel et al. 1984); para o ligamento colateral medial e para o tendão patelar de fetos bovinos ( $>280$ dias gestação), de fetos felinos ( $>60$ dias gestação), de fetos de ratos ( $>21$ dias gestação) e de ratos adultos (Provenzano \& Vanderby Jr 2006); para o ligamento colateral medial, para o tendão patelar e para o tendão calcâneo comum de ratos da raça Sprague Dawley (Franchi et al. 2010a) também foram verificados nos ligamentos colaterais lateral e medial do joelho da paca.

A organização paralela, a orientação longitudinal ao eixo do ligamento e o agrupamento em feixes das fibras de colágeno contribuem para resistência dos ligamentos à carga de tração aplicada de um osso a outro durante o movimento (Provenzano \& Vanderby Jr 2006, Franchi et al. 2010b).

As ondulações das fibras de colágeno possibilitam resistência ao ligamento durante o estiramento (Franchi et al. 2010a, Franchi et al. 2010b). Estas ondas evitam o rompi- 
mento do ligamento, desde que o estiramento ocorra dentro dos limites normais (Viidik \& Ekholm 1968, Frank et al. 1985, Benjamin \& Ralphs 1997).

Assim como observado no ligamento cruzado cranial de seres humanos (Clark \& Sidles 1990, Strocchi et al. 1992); no ligamento cruzado cranial de coelhos (Bayat et al. 2003) e no ligamento cruzado cranial de ovinos (Meller et al. 2009) também nos ligamentos colaterais lateral e medial do joelho da paca havia tecido conjuntivo frouxo separando e envolvendo os feixes de fibras colágenas longitudinais.

0 aglomerado de células com núcleos de formato irregular e o vaso sanguíneo presente no tecido conjuntivo frouxo dos ligamentos colaterais, lateral e medial do joelho da paca, provavelmente, fazem parte do endoligamento ou epiligamento. Estas estruturas estão envolvidas com a vascularização, estimulo nervoso e fonte celular para cicatrização dos ligamentos (Chowdhury et al. 1991, Georgiev \& Vidinov 2009, Georgiev et al. 2010).

As estriações transversais verificadas nas fibrilas de colágeno dos ligamentos colaterais lateral e medial do joelho da paca são atributos da organização das moléculas de tropocolágeno que constituem as fibrilas colágenas do tipo I (Exposito et al. 2002).

Estas estriações são determinadas pelo arranjo das moléculas de tropocolágeno que se sobrepõe uma a outra, produzindo regiões de sobreposição e lacunar. As regiões de sobreposição das moléculas de tropocolágeno são visibilizadas como faixas claras. Já as regiões lacunares são visibilizadas como faixas escuras devido à retenção de contraste, geralmente chumbo utilizado nas preparações dos tecidos para microscopia eletrônica, pelos radicais químicos livres dos aminoácidos presentes nesta região (Ross et al. 1993, Junqueira \& Carneiro 2008, Ross \& Pawlina 2008).

\section{Meniscos, lateral e medial}

Os meniscos lateral e medial do joelho da paca apresentam constituição fibrocartilaginosa, composto por regiões de tecido conjuntivo denso não modelado e por regiões de cartilagem hialina, semelhante ao encontrado no menisco de coelhos (Ghadially et al. 1978, Graverand et al. 2001), de seres humanos (Ghadially et al. 1983), de bovinos (Cheung 1987), de cães (Kambic \& McDevit 2005) e da capivara (Resoagli et al. 2007).

Os condrócitos e os grupos isógenos observados na cartilagem hialina dos meniscos do joelho do tigre (Ganey et al. 1994, Walker et al. 2002), do leão (Walker et al. 2002, Kirberger et al. 2005), do jaguar, do leopardo, do lince, do puma (Walker et al. 2002) e da capivara (Resoagli et al. 2007) também estavam presentes na cartilagem hialina dos meniscos do joelho da paca.

0 arranjo aparentemente irregular das fibras de colágeno presentes na região fibrocartilaginosa dos meniscos lateral e medial do joelho da paca, assemelham-se ao descrito para os meniscos de seres humanos (Bullough et al. 1970, Aspden et al. 1985), de coelhos (Ghadially et al. 1978), de cães (Somer \& Somer 1983, Aspden et al. 1985, Kambic \& Mcdevit 2005), e de suínos mini pig (Aspden et al. 1985).

Neste arranjo aparentemente irregular, algumas fibras colágenas apresentam orientação circunferêncial, enquan- to outras fibras colágenas têm orientação radial. Estes dois tipos de orientações associadas formam uma rede de fibras colágenas, que confere resistência ao menisco para suportar tensão e resistir a rupturas (Bullough et al. 1970, Aspden et al. 1985).

Assim como observado nos meniscos do joelho de coelhos (Ghadially et al. 1978, Shibuya 1999), de seres humanos (Ghadially et al. 1983) e de cães (Somer \& Somer 1983), nos meniscos do joelho da paca as células predominantes foram os condrócitos e fibroblastos.

É possível encontrar células em fases transitórias na diferenciação de fibroblasto em condrócito, onde o fibroblasto deixa de ser alongado e achatado e converte-se em uma célula de formato ovoide a redonda. Este processo de transformação ocorre principalmente nas cartilagens em crescimento ou em desenvolvimento (Ross et al. 1993).

\section{CONCLUSÕES}

Os ligamentos colaterais, lateral e medial do joelho da paca, são estruturalmente análogos aos ligamentos e tendões dos mamíferos domésticos, roedores, lagomorfos e também seres humanos.

Os meniscos, lateral e medial do joelho da paca, microscopicamente, possuem constituição similar aos meniscos dos mamíferos domésticos, roedores, lagomorfos e seres humanos.

\section{REFERÊNCIAS}

Amiel D., Frank C., Harwood F., Fronek J. \& Akeson W. 1984. Tendons and ligaments: a morphological and biochemical comparison. J. Orthop. Res. 1:257-265.

Aspden R.M., Yarker Y.E. \& Hukins D.W.L. 1985. Collagen orientations in the meniscus of the knee joint. J. Anat. 140:371-380.

Bayat M., Mohammadzade F. \& Rakhshan M. 2003. Electron and light microscopic study of anterior cruciate ligament of rabbit. J. Anat. Soc. India 52:155-158.

Benjamin M. \& Ralphs J.R. 1997. Tendons and ligaments - an overview. Histol. Histopathol. 12:1135-1144.

Bradley O.C. 1959. Topographical anatomy of the dog. $6^{\text {th }}$ ed. Oliver and Boyd, London. 332p.

Bullough P.G., Munuera L., Murphy J. \& Weinstein A.M. 1970. The strength of the menisci of the knee as it relates to their fine structure. J. Bone Joint Surg. 52:564-570

Clark J.M. \& Sidles J.A. 1990. The interrelation of fiber bundles in the anterior cruciate ligament. J. Orthop. Res. 8:180-188.

Cheung H.S. 1987. Distribution of type I, II, III and V in the pepsin solubilized collagens in bovine menisci. Connect. Tissue Res. 16:343-356.

Chowdhury R., Matyas J.R. \& Frank C.B. 1991. The 'epiligament' of the rabbit medial collateral ligament: a quantitative morphological study. Connect. Tissue Res. 27:33-50.

Exposito J.Y., Cluzel C., Garrone R. \& Lethias C. 2002. Evolution of collagens. Anat. Rec. 268:302-316.

Franchi M., Ottani V., Stagni R. \& Ruggeri A. 2010a. Tendon and ligament fibrillary crimps give rise to left-handed helices of collagen fibrils in both planar and helical crimps. J. Anat. 216:301-309.

Franchi M., Quaranta M., Macciocca M., Leonardi L., Ottani V., Bianchini P., Diaspro A. \& Ruggeri A. 2010b. Collagen fibre arrangement and functional crimping pattern of the medial collateral ligament in the rat knee. Knee Surg. Sports Traumatol. Arthrosc. 18:1671-1678.

Frank C., Amiel D., Woo S.L.Y \& Akeson W. 1985. Normal ligament properties and ligament healing. Clin. Orthop. Relat. Res. 196:15-25. 
Ganey T.M., Ogden J.A., Abou-Madi N., Colville B., Zdyziarski J.M. \& Olsen J.H. 1994. Meniscal ossification. II. The normal pattern in the tiger knee. Skeletal Radiol. 23:173-179.

Georgiev G.P. \& Vidinov N.K. 2009. Investigation on the epiligament morphology of the lateral collateral ligament during postnatal development in rat knee model. CR Acad. Bulgare. Sci. 62:1473-1478.

Georgiev G.P., Vidinov N.K. \& Kinov P.S. 2010. Histological and ultrastructural evaluation of the early healing of the lateral collateral ligament epiligament tissue in a rat knee model. BMC Musculoskelet. Disord. 11:117.

Ghadially F.N., Thomas I., Yong N. \& Lalonde J.M.A. 1978. Ultrastructure of rabbit semilunar cartilages. J. Anat. 125:499-517.

Ghadially F.N., Lalonde J. \& Wedge J.H. 1983. Ultrastructure of normal and torn menisci of the human knee joint. J. Anat. 136:773-791.

Graverand M.P.H.L., Ou Y., Schield-Yee T., Barclay L., Hart D., Natsume T. \& Rattner J.B. 2001. The cells of the rabbit meniscus: their arrangement, interrelationship, morphological variations and cytoarchitecture. J. Anat. 198:525-535.

Junqueira L.C \& Carneiro J. 2013. Histologia básica. 12aㅡ ed. Guanabara Koogan, Rio de Janeiro. 556p.

Kambic H.E. \& Mcdevit C.A. 2005. Spatial organization of types I and II collagen in the canine meniscus. J. Orthop. Res. 23:142-149.

Kirberger R.M., Plessis W.M. \& Turner P.H. 2005. Radiologic anatomy of the normal appendicular skeleton of the lion (Panthera leo). 2. Pelvic limb. J. Zoo Wildl. Med. 36:29-35.

Leal L.M., Freitas H.M., Sasahara T.H.C. \& Machado M.R.F. 2014. The hindlimb arterial vessels in Lowland paca (Cuniculus paca Linnaeus, 1766). Anat. Histol. Embryol. DOI:10.1111/ahe.12160

Matamoros Y. 1982. Investigaciones preliminares sobre la reproducción, comportamiento, alimentación y manejo tapezcuinte (Cuniculus paca Brisson) en cativeiro en Salinas. In: VIII Congreso Latinoamericano de Zoología, Salinas. Anais Salinas: Zoología Neotropical 902-961.

Mondolfi E. 1972. La Lapa o paca - Mamíferos de caza de Venezuela. Defensa De la Naturaleza 2:4-16.

Meller R., Schiborra F., Brandesb G., Knoblochc K., Tschernigd T., Hankemeiera S., Haaspera C., Schmiedld A., Jagodzinskia M., Kretteka C. \& Willbolde E. 2009. Postnatal maturation of tendon, cruciate ligament, meniscus and articular cartilage: a histological study in sheep. Ann. Anat. 191:575-585.
Mendes E. \& Silva M.V. 2006. Anatomy of the lateral collateral ligament: a caver and histological study. Knee Surg. Sports Traumatol. Arthrosc. 14:221-228.

Provenzano P.P. \& Vanderby Jr R. 2006. Collagen fibril morphology and organization: implications for force transmission in ligament and tendon. Matrix Biol. 25:71- 84.

Resoagli E.H., Bode F.F., Flores-Quintana C., Resoagli J.M., Millán S.G. \& Cao J.A. 2007. Anatomia de la unión femorotibiopatelar em el carpincho (Hydrochoerus hydrochaeris Linnaeus, 1766). Vet. Rev. 18:20-23.

Ross M.H. \& Pawlina W. 2008. Histologia: texto e atlas em correlação com biologia celular e molecular. Guanabara Koogan, Rio de Janeiro. 908p.

Ross M.H., Reith E.J. \& Romrell L.J. 1993. Histologia: texto e atlas. $2^{\underline{a}}$ ed. Panamericana, São Paulo. 779p.

Romão M.S.C., Bezerra F.M.P. \& Porto A.O. 2011. Modelo cirúrgico experimental de exérese de tumor cutâneo em abdome de suíno. $3^{\circ}$ Encontro Universitário da UFC no Cariri, Juazeiro do Norte, CE.

Santos B.F. 2006. Modelo animal, p.23-24. In: Andrade A., Pinto S.C. \& Oliveira R.S. (Eds), Animais de Laboratório: criação e experimentação. Fiocruz, Rio de Janeiro.

Shibuya S. 1999. Meniscus transplantation using a cryopreserved allograft: histological and ultrastructural study of the transplanted meniscus. J. Orthop. Sci. 4:135-141.

Silva F. 1994. Mamíferos silvestres do Rio Grande do Sul. $2^{\text {a }}$ ed. Fundação Zoobotânica do Rio Grande do Sul, Porto Alegre. 264p.

Strocchi R., Pasquale V., Gubellini P., Facchini A., Marcacci M., Buda R., Zaffagnini S. \& Ruggeri A. 1992. The human anterior cruciate ligament: histological and ultrastructural observations. J. Anat. 180:515-519.

Somer L. \& Somer T. 1983. Is the meniscus of the knee joint a fibrocartilage? Acta Anat. 116:234-244.

Tolosa E.M.C., Behmer O.A \& Freitas-Neto A.G. 2003. Manual de técnicas para histologia normal e patológica. Manole, Barueri. 331p.

Viidik A. \& Ekholm R. 1968. Light and electron microscopic studies of collagen fibers under strain. Anat. Embryol. 127:154-164.

Vitorino M. 1979. Técnica Histológica. 2ª ed. Atheneu, São Paulo. 246p.

Walker M., Phalan D., Jensen J., Johnson J., Drew M., Samii V., Henry G. \& Mccauley J. 2002. Meniscal ossicles in large non-domestic cats. Vet. Radiol. Ultrasound. 43:249-254. 